Original Research Paper

\title{
Knowledge of Chemical Hazards and Prevalence of Darkroom Diseases among Darkroom Technicians and Assistants in Southeast, Nigeria
}

\author{
Mark C. Okeji, Felicitas U. Idigo, AngelMary C. Anakwue and Uloma Nwogu \\ Department of Medical Radiography and Radiological Sciences, \\ Faculty of Health Sciences and Technology, University of Nigeria, Enugu Campus Nigeria
}

\author{
Article history \\ Received: 8-7-2015 \\ Revised: 28-9-2015 \\ Accepted: 24-11-2015 \\ Corresponding Author: \\ Mark C. Okeji \\ Department of Medical \\ Radiography and Radiological \\ Sciences, Faculty of Health \\ Sciences and Technology, \\ University of Nigeria, Enugu \\ Campus Nigeri \\ Tel: +234-8039472126 \\ Email: markokeji@yahoo.com, \\ mark.okeji@unn.edu.ng
}

\begin{abstract}
Darkroom technicians and assistants are exposed daily to x-ray processing chemicals. These chemicals contain known irritants which can cause some disease symptoms to its handlers. The aim of this study was to assess the knowledge of chemical hazards and prevalence of darkroom diseases among darkroom technicians and assistants in Southeast, Nigeria. The study adopted cross-sectional survey. A total of 105 darkroom technicians and assistants who met the inclusion criteria in the 10 tertiary hospitals in Southeast, Nigeria were enlisted in the study. Data were collected using researcher-developed questionnaire and on-the-spot assessment of adequacy of ventilation in the darkroom. The questionnaire sought data on demographic variables, knowledge of the constituents of the processing chemicals, adherences to operating guidelines, knowledge of possible side effects, any observed sudden episodes of ill health and presence of workshops for new employees and older staff. The reliability of the instrument was conducted using test re-test in two tertiary hospitals in Southwest Nigeria. The internal consistency was calculated using Cronbach alpha which yielded a co-efficient of 0.82 . A total of 105 questionnaires were administered and 100 copies properly completed and returned giving a return rate of $95.2 \%$. $72 \%$ of the respondents had knowledge (mean $=3.20 \pm 0.71$ ) of chemical hazard associated with $\mathrm{x}$-ray processing chemicals while $34 \%$ had knowledge (mean $=3.12 \pm 1.3$ ) of the constituents of the processing chemicals. Forty-four respondents (44\%) always read the enclosed Materials Safety Data Sheet (MSDS) $($ mean $=2.57 \pm 1.1)$ before mixing the chemicals. The prevalence of darkroom disease among darkroom technicians and assistant in Southeast, Nigeria from our study was $68 \%$. There were no significant differences $(p>0.05)$ on the knowledge of darkroom disease, constituents of the processing chemicals and attention to Material Safety Data Sheet (MSDS) among darkroom technicians and assistants of different educational levels. There was high knowledge of chemical hazards among darkroom technicians and assistants from our study. However poor knowledge of the constituents of the processing chemicals and poor attention to the MSDS were noted to contribute to increase in the prevalence of the diseases.
\end{abstract}

Keywords: Darkroom Disease, Darkroom Technicians and Assistants, Respiratory Symptoms

\section{Introduction}

Image processing chemicals help to convert latent images formed on radiographic films to visible images. The chemicals convert the silver halides which are part of the emulsion coating on radiographic films to silver ions and metallic silver. The two major components of the processing chemicals are the developers and the fixers, which may either be in powdered or liquid form. These chemicals contain glutaraldehyde, formaldehyde, hydroquinone, sulphur dioxide, glycols, ammonium chloride and acetic acid (Teschke et al., 2002; Johnston 
and Killion, 2006). The constituents of the processing chemicals are known irritants and could cause or exacerbate symptoms such as headache, skin rashes, asthma, nasal and pharyngeal irritation, sore throat, shortness of breath, runny nose and cough in humans (Byrns et al., 2000; Tomoko and Yoko, 2006; Nayebzader, 2007; Kakooei et al., 2007). These symptoms are part of multiple symptoms referred to as darkroom diseases or multiple-chemical sensitivity (Sanchez, 1999). Darkroom diseases describe a collection of symptoms experienced by radiographers and darkroom technicians when exposed to x-ray film processing chemicals (Spicer et al., 1986; Hewitt, 1993; Nallon et al., 2000; Liss et al., 2003; Tarlo et al., 2004). Some occupational factors such as the period of stay per shift in the darkroom was reported by Al Zabadi and Nazzal (2014) to have a strong significant association with the mean number of reported symptoms. Their study showed that staying more than $30 \mathrm{~min}$ in the darkroom per shift was associated with a significant increase in the mean number of reported symptoms. Similarly, Al-Ajerami and Sirdah (2008) had reported from their study in Gaza strip that radiographers at high risk of developing darkroom disease symptoms were those who spend long periods $(>10 \mathrm{~h}$ per week) in diagnostic imaging departments.

Many developing countries are yet to undergo transition to digital image processing. In Nigeria most of the radiology departments are still operating the darkroom processing techniques. This is contrary to the digital image processing that has eliminated the application of processing chemical.

The knowledge of chemical hazards and prevalence of respiratory symptoms among darkroom technicians and assistants are yet to be ascertained in Southeast, Nigeria. Therefore, this study sought to determine the knowledge of chemical hazards and prevalence of darkroom diseases among darkroom technicians and assistants in Southeast, Nigeria. It also aimed at explaining the relationship between exposure to the chemicals and work related symptoms.

\section{Methodology}

The study adopted cross sectional descriptive survey design. There were 165 darkroom technicians and assistants working in the 10 tertiary hospitals located in Southeast, Nigeria. The Southeast Nigeria has five states namely; Abia, Anambra, Ebonyi, Enugu and Imo with two tertiary hospitals domiciled in each state. Each of the ten hospitals was visited by the researchers and the darkroom technicians and assistants privately interviewed. A total of 105 darkroom technicians and assistants who met the inclusion criteria were enlisted into the study. The instrument for data collection was a researcher-developed structured questionnaire. The questionnaires consist of section $\mathrm{A}$ and $\mathrm{B}$. Section $\mathrm{A}$ elicited information on demographic variables while section B sought data on knowledge of the constituents of the processing chemicals, adherences to operating guidelines, knowledge of possible side effects, any observed sudden episodes of ill health, list of symptoms of darkroom diseases to choose and presence of workshops for new employees and older staff. The questions were based on four point $($ mean $=2.5)$ and five point $($ mean $=3.0)$ rating scales. The questionnaire was validated by three experts in the Department of Medical Radiography and Radiological Sciences, University of Nigeria, Enugu Campus. The reliability was conducted using test re-test in two tertiary hospitals in Southwest Nigeria. The internal consistency was calculated using Cronbach alpha which yielded a co-efficient of 0.82 . The questionnaires were personally administered to the respondents by the researchers. Also on-the-spot assessments of adequacy of ventilation in the darkrooms were undertaken by the researchers. The ventilation was adjudged poor (if there was no window or air exhaust machine), fair (if there was a window) and adequate (if there was a window and an air exhaust machine). Data was subjected to descriptive statistics and analyzed using Analysis of Variance (ANOVA). Probability value $(p<0.05)$ was considered statistically significant.

\section{Results}

A total of 105 questionnaires were administered and 100 copies properly completed and returned giving a return rate of $95.2 \%$. Eight three percent $(83 \%)$ of the respondents were males while $17 \%$ were females, $52 \%$ of the darkroom technicians and assistants were within the age range of 31 to 40 years. Majority of the respondents $(82 \%)$ have working experience ranging from six to thirty four years while $91 \%$ of the respondents have educational qualification ranging from Senior Secondary School Certificate to degree.

A total of $72(72 \%)$ of the respondents had knowledge $($ mean $=3.20 \pm 0.71)$ of chemical hazard associated with $\mathrm{x}$-ray processing chemicals while $34 \%$ had knowledge (mean $=3.12 \pm 1.3$ ) of the constituents of the processing chemicals. Forty-four respondents (44\%) always read the enclosed Materials Safety Data Sheet $($ MSDS $)($ mean $=2.57 \pm 1.1)$ before mixing the chemicals. Only $21 \%$ of the respondents had attended update-workshops $($ mean $=2.61 \pm 0.81)$ on darkroom practice as employees. Forty-nine respondents (49\%) had knowledge of darkroom diseases (mean = $2.57 \pm 1.2$ ) while $31 \%$ reported presence of protective devices $(2.72 \pm 0.82)$ in their hospitals. Sixty-eight respondents $(68 \%)$ had suffered one or more of the darkroom diseases. The most frequently suffered diseases were cough (68\%) followed by headache $(65 \%)$ and catarrh/nasal discharge $(53 \%)$. The least experienced disease condition was diarrhea (12\%). 
Table 1. Demographic information of the 100 respondents

\begin{tabular}{ll}
\hline Characteristics & Frequency \\
\hline Sex & \\
Male & $83(83 \%)$ \\
Female & $17(17 \%)$ \\
Age (years) & \\
$20-30$ & $19(19 \%)$ \\
$31-40$ & $52(52 \%)$ \\
$41-50$ & $13(13 \%)$ \\
$51-59$ & $16(16 \%)$ \\
Years of practice & \\
$1-5$ & $18(18 \%)$ \\
$6-10$ & $27(27 \%)$ \\
$11-15$ & $14(14 \%)$ \\
$16-20$ & $11(11 \%)$ \\
$21-25$ & $6(6 \%)$ \\
$26-30$ & $8(8 \%)$ \\
$31-34$ & $16(16 \%)$ \\
Educational Qualification & \\
Primary six with trade test & $9(9 \%)$ \\
Secondary school (O' level) & $76(76 \%)$ \\
Diploma degree & $12(12 \%)$ \\
Degree (HND, B.Sc) & $3(3 \%)$ \\
\hline
\end{tabular}

Table 2. Knowledge of dangers and constituents of processing chemicals

Knowledge of constituent of processing chemicals $34(34 \%)$

Underwent training before assumption of duty $\quad 59(59 \%)$

Always read the enclosed literature before 44 (44\%)

mixing chemicals (Material Safety Data Sheet, MSDS)

Attend periodic workshop on darkroom practice $21(21 \%)$

Knowledge of darkroom disease $\quad 49(49 \%)$

Availability of protective devices in the hospital $\quad 31(31 \%)$

Had suffered an episode of darkroom disease in the past $68(68 \%)$

Table 3.Distribution of darkroom disease experienced by the respondents

\begin{tabular}{ll}
\multicolumn{1}{c}{ respondents } & No of respondents \\
Disease & $59(59 \%)$ \\
\hline Nausea & $17(17 \%)$ \\
Sinusitis & $65(65 \%)$ \\
Headache & $16(16 \%)$ \\
Respiratory distress & $51(51 \%)$ \\
Sore throat & $68(68 \%)$ \\
Cough & $12(12 \%)$ \\
Diarrhea & $53(53 \%)$ \\
Catarrh/nasal discharge &
\end{tabular}

Physical observation revealed poor ventilation pattern in $60 \%$ of the hospitals. These include lack of window for cross ventilation during mixing of chemicals and absence of active air circulation mechanism (Table 1-3).

\section{Discussion}

The prevalence of darkroom disease among darkroom technicians and assistant in Southeast, Nigeria from our study was $68 \%$. However the presence of the various symptoms ranges from $16 \%$, for respiratory distress, to $68 \%$ for cough. The prevalence from our study is higher than that of Nhivativa et al. (2014) and Chingavande et al. (2013) who conducted similar studies among darkroom technicians. The differences may be due to the lower number of respondents in their studies and possible influence of environmental factors, such as dusty haze (experienced during dry season in our locality) and ventilation patterns in the darkrooms, which they did not assess. Poor ventilation in darkroom had been documented to result in severe respiratory disorder and job loss in the USA (Sanchez, 1999). However Al Zabadi and Nazzal (2014) found higher prevalence among radiographers in their study. The higher prevalence among radiographers could be due to increased workload occasioned by absence of darkroom technicians. The high percentage of respondents who suffered from cough and catarrh/nasal discharge in our study may be attributed to the poor provision of protective devices $(31 \%)$ in the hospitals and poor ventilation pattern witnessed. It could also be due to poor attention to instructions in the enclosed Material Safety Data Sheet (MSDS).

There were no significant differences $(p>0.05)$ on the knowledge of darkroom disease, constituents of the processing chemicals and attention to MSDS among darkroom technicians and assistants of different educational levels. The poor knowledge of the constituent of the processing chemicals may not be due to low educational qualification $(91 \%$ had Senior Secondary School Certificate and above). It could be attributed to poor attention to the Material Safety Data Sheet (MSDS) enclosed in the packaging for the chemicals and few numbers of workshops for the darkroom technicians and assistants.

Strength of the Study: The prevalence of $68 \%$ from our study has significant negative health implication for the work force. Increased upper respiratory disorder was noted in centres where ventilation in the darkrooms was compromised and no protective devices provided. It is possible that irritation due to exposure to glutaraldehyde, formaldehyde, sulphur dioxide and acetic acid may account for presence of these disorders.

Limitations of the study: Our study did not categorize the respondents based on family history of asthma or history of smoking. Our findings were based on selfreported symptoms by the darkroom technicians and assistants and not objectively assessed by a physician. Possible reporting bias could not however be excluded. An objective assessment and a change to digital processes and follow-up of these workers will elucidate the findings from this study.

\section{Conclusion}

High knowledge of chemical hazards associated with $\mathrm{x}$-ray processing chemicals was observed from our study. However poor knowledge of the constituents of the processing chemicals was discovered. This may not be due to low educational qualification of the darkroom 
technicians and assistants but inadequate numbers of workshops and less attention paid to the enclosed MSDS by the technicians and assistants. The prevalence of darkroom diseases among the technicians and assistance was $68 \%$. There was poor ventilation in most of the darkrooms studied. Concerted efforts should be made to organize periodic workshops to educate the technicians and assistants. There should be provision of protective devices for the darkroom workers. Mitigation measures to ensure adequate ventilation in the darkrooms should be carried out. Periodic health checks should be conducted on the darkroom technicians and assistants.

\section{Acknowledgement}

The authors are grateful to Ochomma, Blessing for her assistance in data collection.

\section{Funding Information}

No research fund was utilized for this study.

\section{Author Contributions}

Mark C. Okeji: Designed the research plan and coordinated data analysis and manuscript writing.

Felicitas U. Idigo, AngelMary C. Anakwue and Uloma Nwogu: Participated in data collection and analysis.

\section{Conflict of Interest}

The authors have no conflicts of interest.

\section{References}

Al-Ajerami, Y. and M. Sirdah, 2008. Effects of x-ray film processing on health status of medical radiographers at Gaza Strip, Palestine. J. Al Azhar Univ. Gaza. (Nat. Sci.). 10: 59-76.

Al Zabadi, H. and Y. Nazzal, 2014. Evaluation of darkroom disease's symptoms among radiographers in West bank hospitals: A cross-sectional study in Palestine. J. Occupational Medicine Toxicology, 9: 15. DOI: 10.1186/1745-6673-9-15

Byrns, G.E., K.H. Palatianos, L.A. Shands, K.P. Fennelley and C.S. McCammon et al., 2000. Chemical hazards in radiology. Appl. Occup Environ. Hyg., 15: 203-203. DOI: $10.1080 / 104732200301700$

Chingavande, G., T. Bunga, C. Mukwusi, J. Banhwa and F. Majpnja et al., 2013. The prevalence and severity of the symptoms of darkroom disease among darkroom technicians in harare, Zimbabwe. World J. Med. Sci., 8: 113-117.

DOI: 10.5829/idosi.wjms.2013.8.2.7319
Hewitt, P.J., 1993. Occupational health problem in processing of photographic film. Ann. Occupational Hygiene, 37: 287-295.

DOI: 10.1093/annhyg/37.3.287

Johnston, J.N. and J.B. Killion, 2006. Hazards in the radiology department. Radiol. Technol., 76: 417-423. PMID: 16116889

Kakooei, H., M.B. Ardakani and A. Sadighi, 2007. Determinants of exposure to chemical pollutants in wet x-ray film processing in Iran. Pak J. Biol. Sci., 15: 10: 2341-2347. PMID: 19070154

Liss, G.M., S.M. Tarlo, J. Doherty, J. Purdham and L. Greene et al., 2003. Physician diagnosed asthma, respiratory symptoms and associations with workplace tasks among radiographers in Ontario, Canada. Occupational Environ. Med., 60: 254-261. DOI: 10.1136/oem.60.4.254

Nallon, B.H. and P.C. Brennam, 2000. Do symptomatic radiographers provide evidence for 'darkroom diseases'? Occupational Med., 50: 39-42. DOI: $10.1093 /$ occmed/50.1.39

Nayebzader, A., 2007. The effect of work practices on personal exposure to glutaraldehyde among health care workers. Ind. Health, 45: 289-295. PMID: 17485873

Nhivativa, F., C. Mukwasi and G. Chingavanda, 2014. Respiratory status of darkroom Technicians working in various radiology departments in Harare, Zimbabwe. Int. J. Sci.: Basic Applied Res., 18: 286-296.

Sanchez, T., 1999. When it hurts to breathe: Chemicals and R.Ts. ASRT Scanner, 11: 6-8.

Spicer, J., D. Hay and M. Gordon, 1986. Workplace exposure and reported health in New Zealand diagnostic radiographers. Australas Radiol., 30: 281-286. DOI: $10.1111 /$ j.1440-1673.1986.tb01753.x

Tarlo, S.M., G.M. Liss, J.M. Greene, J. Purdham and L. McCaskell et al., 2004. Work-attributed symptom clusters (darkroom disease) among radiographers versus physiotherapists: Association between selfreported exposures and psychosocial stressors. Am. J. Ind. Med., 45: 513-521. DOI: 10.1002/ajim.20015

Teschke, K., Y. Chow, M. Beauer, E. Chessor and B. Hirtle et al., 2002. Exposures and their determinants in radiographic film processing. Am. Ind. Hyg. Assoc. J., 63: 11-21.

DOI: $10.1080 / 15428110208984686$

Tomoko, T. and E. Yoko, 2006. Effects of glutaraldehyde exposure on human health. J. Occupational Health, 48: 75-87.

DOI: $10.1539 /$ joh.48.75 